\title{
PROPOSTA DE IMPLANTAÇÃO DE UMA METODOLOGIA INTEGRADA A PARTIR DO ESTUDO DA COMPLEMENTARIDADE E DA COMPATIBILIDADE DA GESTÃO POR PROCESSOS E DA MANUFATURA ENXUTA
}

\author{
Guilherme Brittes Benitez. \\ Graciele Rediske ${ }^{2}$ \\ Joici Paloma Genro ${ }^{3}$ \\ Fernanda Iserhard ${ }^{4}$ \\ Bruna Bueno Mariani ${ }^{5}$ \\ Liane Mahlmann Kipper ${ }^{6}$ \\ Elpídio Oscar Benitez Nara ${ }^{7}$
}

\begin{abstract}
RESUMO
Buscou-se com esta pesquisa o desenvolvimento de uma nova metodologia de implantação que interaja com a tecnologia de informação e a flexibilização da manufatura através das metodologias de gerenciamento: gestão por processo e manufatura enxuta. A análise destas metodologias deu-se por dois aspectos: em quais elas são complementares e elas são compatíveis. Foram utilizados métodos quantitativos e qualitativos. Com relação à forma de levantamento de dados pode-se classificar esta pesquisa como exploratória e um estudo de caso. Para esta aplicação foi realizado um estudo de caso em uma empresa de médio porte que atua no ramo de embalagens plásticas. Com o resultado da pesquisa foi possível identificar a compatibilidade e complementariedade entre as duas ferramentas de gerenciamento e a partir deste ponto, foi desenvolvida uma nova metodologia, sendo identificados alguns pontos onde a informação ainda é ineficiente e o desperdício de matéria-prima e de tempo é alto.
\end{abstract}

Palavras-chave: Manufatura Lean. Gestão por processos. Integração de metodologias.

\section{ABSTRACT}

Sought with this research the development of a new methodology of implementation that interacts with the information technology and the easing of manufacture through management methodologies: process management and lean manufacturing. The analysis of these methodologies was given by two aspects: in what aspects they are complementary and what points are compatible. For the development of this research were used quantitative and qualitative methods. Regarding the form of survey data can classify this research as

\footnotetext{
${ }^{1}$ Acadêmico do curso de Engenharia de Produção pela Universidade de Santa Cruz do Sul - UNISC. <guilherme.benitez@ hotmail.com>

${ }^{2}$ Acadêmica do curso de Engenharia de Produção pela Universidade de Santa Cruz do Sul - UNISC. <gra.rediske@ hotmail.com>

${ }^{3}$ Acadêmica do curso de Engenharia de Produção pela Universidade de Santa Cruz do Sul - UNISC. <joicigenro@mx2.unisc.br>

${ }^{4}$ Acadêmica do curso de Engenharia Civil pela Universidade de Santa Cruz do Sul - UNISC. <feiserhard@gmail.com>

${ }^{5}$ Acadêmica do curso de Engenharia Civil pela Universidade de Santa Cruz do Sul - UNISC. <brunamariani@mx2.unisc.br>

${ }^{6}$ Professora do Departamento de Sistemas e Processos Industriais da Universidade de Santa Cruz do Sul UNISC. <liane@unisc.br>

${ }^{7}$ Professor do Departamento de Sistemas e Processos Industriais da Universidade de Santa Cruz do Sul -UNISC. <elpidio@unisc.br>
} 
exploratory and a case study. For this application, a case study was conducted in a mediumsized company that operates in the field of plastic packaging. With the result of the research was possible to identify the compatibility and complementarity between the two management tools: process management and lean manufacturing and from this point the search result was developed a new methodology, where it was identified a few points where information is still inefficient and a waste of time and raw material is high.

Keywords: Lean Manufacturing. Process Management. Integration of methodologies.

\section{INTRODUÇÃO}

Conforme Pereira et al. (2008), acreditava-se que a tecnologia da informação (TI) iria resolver os grandes desafios da indústria. Buscou-se com este trabalho o desenvolvimento de uma nova metodologia de implantação que interaja com a tecnologia de informação e a flexibilização da manufatura através das metodologias de gerenciamento: gestão por processos e manufatura enxuta. A aplicação de TI e os princípios Lean são reivindicados como interdependentes e complementares o quê não é comum, pois a maioria dos pesquisadores trabalha com as abordagens como sendo mutuamente exclusivas, conforme afirmam Riezebos et al. (2009). A análise destas metodologias deu-se por dois aspectos: em quais elas são complementares e em quais elas são compatíveis.

\section{REVISÃO BIBLIOGRÁFICA}

A revisão bibliográfica desta pesquisa tem como finalidade dar uma visão das metodologias: gestão por processos e manufatura enxuta, entendendo os principais conceitos, as ferramentas utilizadas para implantação, bem como as vantagens encontradas nas duas metodologias.

\subsection{Conceitos básicos da Manufatura Enxuta (Lean)}

Para Womack e Jones (2004), o Pensamento Enxuto é uma forma de especificar valor, alinhando a melhor sequência de acordo com o que agrega valor para o cliente final. A manufatura Lean tem como objetivo final: eliminar o desperdício e as atividades sem valor agregados em cada processo de produção ou serviço, focando o cliente (HODGE et al., 2011). Conforme Liker (2004) existem sete (7) desperdícios que a Manufatura Enxuta procura eliminar ou diminuir continuamente: superprodução; espera; transporte desnecessário; processamento desnecessário; excesso de estoque; movimento desnecessário e defeitos. 
Andersson et al. (2006) definem Produção Enxuta como uma abordagem sistemática para identificar e eliminar os desperdícios por meio de um processo de melhoria contínua. Villiers (2006) relata que, de modo geral, a filosofia da Produção Enxuta é reduzir continuamente as perdas em todas as áreas e de todas as formas. Manufatura enxuta é uma filosofia que reduz o tempo passado entre a ordem do cliente e a entrega do produto através da eliminação de toda a forma de perda ou desperdício (ALUKAL, 2003). Mehta e Shah (2005) definem produção enxuta como uma iniciativa, cujo principal objetivo é reduzir o desperdício do esforço humano.

\subsection{Principais ferramentas da Manufatura Lean}

A Manufatura Enxuta se destaca por apresentar diversas ferramentas para serem aplicadas dentro da sua metodologia, dentre elas: a) Os cinco sensos (5S), em português são conhecidos como os sensos de utilização, organização, limpeza, saúde e autodisciplina (VANTI, 1999), b) JIT / Kanban: o objetivo do JIT (just in time) é a produção de produtos livres de defeitos, na quantidade requerida e no tempo certo (GUPTA, AL-TURKI e PERRY, 1999), c) Setup Rápido (SMED): o processo de redução de setup pode ser atingido através do tipo de abordagem tradicional de estudo de trabalho e a aplicação do sistema SMED (Single Minute Exchange of Die) (PATEL, SHAW e DALE, 2001) e d) Total Productive Maintenance - TPM ou Manutenção Produtiva Total - MPT, segundo SHIROSE (1992) pode ser entendido como um sistema utilizado para eliminar perdas, reduzir paradas, garantir a qualidade e diminuir custos nos processos das organizações. O propósito do TPM é atingir o menor número possível de acidentes, defeitos e avarias.

\subsection{Vantagens da Manufatura Lean}

O balanceamento da linha, o nivelamento do mix e a redução dos estoques permite à empresa enxuta reduzir lead time, ou seja, reduzir o tempo entre o momento de entrada do material até a sua saída do inventário (LAMBERT et al., 1998). Este balanceamento permite atender o mercado na sua exigência de tempo de resposta. A redução do tempo é o foco principal da Manufatura Enxuta (ALVES, 2001). Na Manufatura Lean, o mapeamento de atividade do processo é a ferramenta mais adequada para alcançar uma rápida melhoria na produtividade no chão de fábrica e maximizar o retorno sobre o esforço (RAMESH e KODALI, 2012). 


\subsection{Conceito da Gestão por Processo}

As organizações orientadas por processos devem ultrapassar as barreiras organizacionais por meio da liderança do processo em todas as áreas da empresa (FREDERICO E TOLEDO, 2008). Segundo Candido et al. (2008) para que tenhamos uma visão sistêmica é interessante que este mapeamento considere os seguintes níveis dos processos e suas relações: Macro Processo, Processo, Sub-Processo e Atividades.

\subsection{Principais ferramentas da Gestão por Processo}

A Gestão por Processo busca entender o fluxo do processo e os seus relacionamentos. Para aplicar esta metodologia são necessárias algumas ferramentas, dentre elas: a) Brainstorming: É uma técnica de geração de ideias, desenvolvida em equipe; b) Fluxogramas: É um tipo de diagrama e pode ser entendido como uma representação esquemática de um processo; c) Mapeamento dos processos: é a ferramenta de visualização completa e consequente compreensão das atividades executadas num processo, assim como da inter-relação entre elas e o processo e é a estrutura básica para a Análise de Processo de Negócios; d) Modelos de maturidade: é uma ferramenta que pode auxiliar as organizações a se tornarem mais bem sucedidas com a utilização da gestão por processos. Modelos de maturidade de processos é um importante instrumento para que as organizações possam identificar em que nível está o seu processo de implantação do modelo de Gestão por Processos (KIPPER e NARA, 2010).

\subsection{Vantagens da Gestão por Processo}

A gestão de processos pode ser implantada em uma organização e ser ponto de partida para a melhoria contínua dos processos produtivos, aumentando a eficiência e, consequentemente, minimizando perdas e maximizando lucros (LOPES, BEZERRA 2008). Segundo Jacobs et al. (2009) a gestão por processos possibilita à organização atuar com eficiência nos recursos e com eficácia nos resultados.

\subsection{Gestão por Processos x Manufatura Enxuta}

Após o estudo das metodologias de gestão por processos e manufatura enxuta, foi possível construir o quadro 01 , que apresenta aspectos que demonstram a compatibilidade e a complementaridade entre elas. 
Quadro 1 - Estudo complementaridade e compatibilidade da Gestão por Processos e da Manufatura Enxuta

\begin{tabular}{|c|c|c|c|}
\hline ASPECTOS & $\begin{array}{l}\text { MANUFATURA } \\
\text { ENXUTA }\end{array}$ & $\begin{array}{l}\text { GESTÃO POR } \\
\text { PROCESSO }\end{array}$ & $\begin{array}{l}\text { COMPLEMENTARIEDADE \& } \\
\text { COMPATIBILIDADE }\end{array}$ \\
\hline OBJETIVOS & Eliminar desperdício & Alinhar o processo & $\begin{array}{l}\text { A GP (Gestão por Processos) } \\
\text { complementa a ME (Manufatura } \\
\text { Enxuta), no sentido de identificar } \\
\text { todos os pontos de desperdício do } \\
\text { mapeamento dos processos }\end{array}$ \\
\hline PRINCIPIOS & $\begin{array}{c}\text { Especificação do que é } \\
\text { Valor para cada } \\
\text { produto; } \\
\text { Identificar o Fluxo de } \\
\text { Valor de cada produto; } \\
\text { Fazer com que o Fluxo } \\
\text { de Valor não tenha } \\
\text { interrupções; } \\
\text { Deixar o cliente puxar o } \\
\text { fluxo de valor; } \\
\text { Buscar a Perfeição }\end{array}$ & $\begin{array}{l}\text { Estudar o fluxo do } \\
\text { processo, como } \\
\text { identificar pontos que } \\
\text { agregam valor ao } \\
\text { cliente e buscar } \\
\text { constantemente com } \\
\text { as equipes } \\
\text { "Stakeholders" ou } \\
\text { agentes do processo a } \\
\text { melhoria contínua dos } \\
\text { processos }\end{array}$ & $\begin{array}{c}\text { Observou-se compatibilidade entre } \\
\text { os princípios apresentados nas } \\
\text { metodologias }\end{array}$ \\
\hline PROCESSOS & $\begin{array}{c}\text { Parcerias de Longo } \\
\text { Prazo: as relações de } \\
\text { parceria entre os } \\
\text { membros da cadeia são } \\
\text { fortalecidas } \\
\text { continuamente }\end{array}$ & $\begin{array}{l}\text { Integração dos } \\
\text { processos, através de } \\
\text { redes de } \\
\text { relacionamento }\end{array}$ & $\begin{array}{l}\text { A GP vai complementar a ME, pois } \\
\text { irá criar a rede de relacionamento } \\
\text { para melhor entendimento dos } \\
\text { processos por todos os envolvidos } \\
\text { "stakeholders" }\end{array}$ \\
\hline $\begin{array}{l}\text { INDICADORES } \\
\text { DE } \\
\text { DESEMPENHO }\end{array}$ & $\begin{array}{c}\text { Satisfação do } \\
\text { consumidor: ênfase nos } \\
\text { custos e qualidade das } \\
\text { operações }\end{array}$ & $\begin{array}{l}\text { Foco em agregação de } \\
\text { valor para o cliente } \\
\text { interno e externo }\end{array}$ & $\begin{array}{l}\text { A GP vai ao encontro da ME, para } \\
\text { gerar indicadores e controles em } \\
\text { processos que irão agregar valor para } \\
\text { os seus clientes }\end{array}$ \\
\hline ESTRUTURA & $\begin{array}{c}\text { Organização em função } \\
\text { de linhas de produtos; } \\
\text { Hierarquia } \\
\text { organizacional }\end{array}$ & $\begin{array}{l}\text { Organização por } \\
\text { processo com uma } \\
\text { visão horizontal e } \\
\text { sistêmica }\end{array}$ & $\begin{array}{l}\text { Na estrutura proposta pela ME e pela } \\
\text { GP observou-se compatibilidade, } \\
\text { pois a primeira foca a organização } \\
\text { por linha de produto e a outra busca } \\
\text { orientar a organização por processos }\end{array}$ \\
\hline IMPLANTAÇÃO & $\begin{array}{l}\text { A manufatura enxuta } \\
\text { tem como etapas para } \\
\text { sua implantação os } \\
\text { pilares Just in Time, a } \\
\text { Jidoka (automatização } \\
\text { com um toque humano) } \\
\text { e a melhoria contínua } \\
\text { (redução de desperdício } \\
\text { e qualidade total) }\end{array}$ & $\begin{array}{l}\text { A gestão por } \\
\text { processos tem como } \\
\text { etapas mapeamento do } \\
\text { processo, rede de } \\
\text { relacionamento, } \\
\text { avaliar pontos que } \\
\text { agregam valor para o } \\
\text { cliente e programas de } \\
\text { melhoria contínua }\end{array}$ & $\begin{array}{l}\text { A GP }{ }^{1} \text { complementa a } \mathrm{ME}^{2} \text {, no } \\
\text { sentido de auxiliar com o } \\
\text { mapeamento de processos, a } \\
\text { ferramenta Just in Time e facilita o } \\
\text { trabalho dos grupos de melhoria } \\
\text { contínua }\end{array}$ \\
\hline
\end{tabular}

Legenda: GP1 (Gestão por processos); $\mathrm{ME}^{2}$ (Manufatura enxuta)

Fonte: Adaptado de Harrison, Christopher e Van Hoek (1999). 
Da análise do quadro 01 percebe-se que as metodologias são muito complementares e compatíveis, o que leva a buscar o uso compartilhado das mesmas. Já a figura 01 apresenta uma proposta de áreas de compatibilidade entre as metodologias e isto indica que, se uma organização agregar valor aos clientes, conhecer seus fluxos por meio do mapeamento e buscar melhoria contínua, ambas as metodologias alcançariam resultados semelhantes, caso aplicadas de forma sistemática.

\section{Figura 01 - Compatibilidade das metodologias gestão por processo e manufatura enxuta.}

\section{COMPATIBILIDADE}

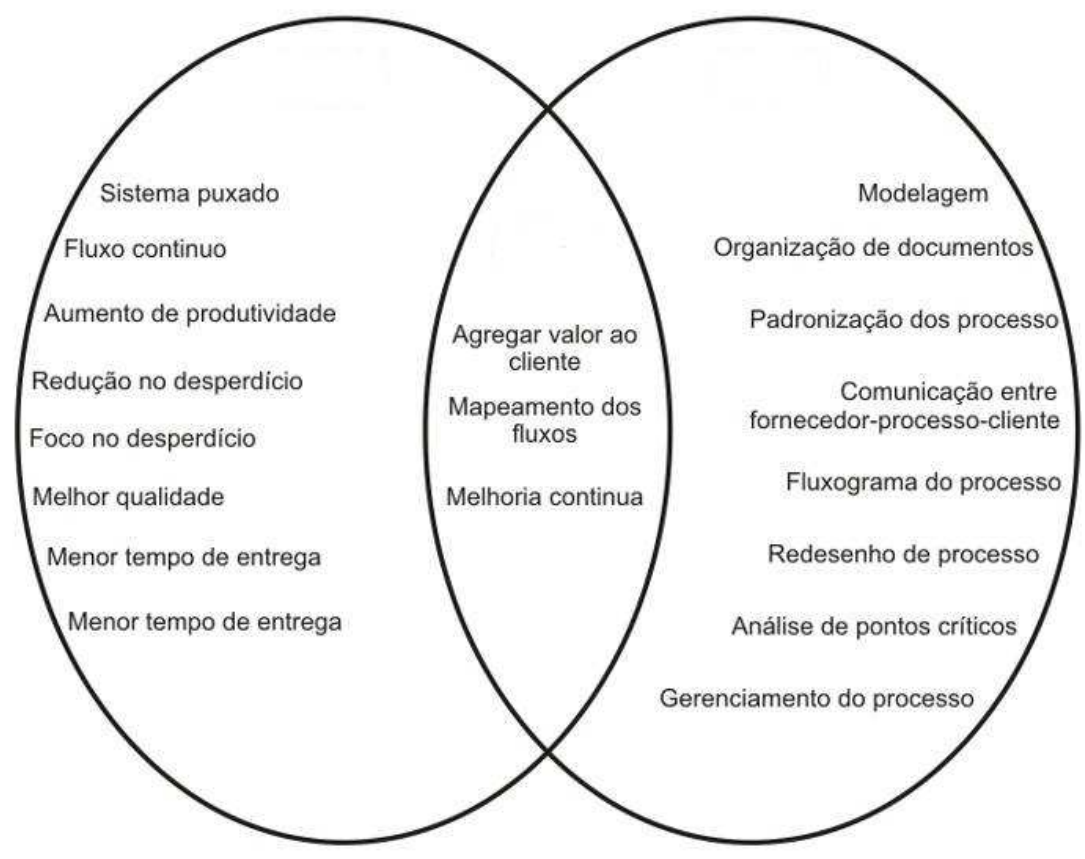

Fonte: Dos autores.

Observando a figura 01, na área do círculo esquerdo, destacaram-se os pontos onde ME tem um melhor resultado e, do mesmo modo, na área do círculo direito, observam-se os pontos que GP realiza para alcançar os melhores resultados. Na interseção dos círculos estão os pontos onde as metodologias acabam se compatibilizando para um melhor gerenciamento do processo produtivo. 


\section{METODOLOGIA}

Para o desenvolvimento desta pesquisa foram utilizados métodos quantitativos para descrever e explicar fenômenos, pois se entende que pesquisar em organizações, relaciona aspectos de caráter social e humano. Considerando o objetivo da pesquisa, que é o desenvolvimento de uma nova metodologia de implantação que interaja com a tecnologia de informação e a flexibilização da manufatura através das metodologias gestão por processo e manufatura enxuta, foi utilizada a abordagem qualitativa (GODOY, 1995; NEVES, 1996). Com relação à forma de levantamento de dados, pode-se classificar esta pesquisa como exploratória e um estudo de caso. O foco da pesquisa qualitativa baseou-se em estudar características na implantação das duas metodologias, analisando qual pode ser a melhor para aplicação que emerge deste estudo. Para a implantação do modelo de gestão por processo, utilizou-se a ideia principal a partir dos aspectos observados como compatíveis entre as duas metodologias, quais sejam: mapeamento dos processos ou dos fluxos, agregar valor ao cliente e melhoria contínua. A partir da definição destes aspectos, foram realizados os seguintes procedimentos metodológicos para realização de um estudo de caso buscando validar o modelo de implantação: construção de uma proposta de implantação da gestão por processos baseada nas metodologias de Manufatura Enxuta e Gestão por Processos e aplicação da proposta em um processo produtivo. Para esta aplicação foi realizado um estudo de caso em uma empresa de médio porte situada no Estado do Rio Grande do Sul, que atua no ramo de embalagens plásticas. O estudo de caso seguiu as seguintes etapas: análise documental, realizada junto a documentos do planejamento estratégico da empresa; avaliação do fluxo de informação, em que foram utilizadas ferramentas como entrevista em forma de questionário junto aos colaboradores envolvidos no processo, e, para avaliar se as informações agregam valor ao cliente, foi realizado um estudo de satisfação dos clientes do processo onde ocorreu o estudo de caso.

\section{DESENVOLVIMENTO}

O desenvolvimento da pesquisa tem a proposta de implantação de uma metodologia integrada para verificar a compatibilidade e complementariedade do processo de manufatura, que foi aplicado a uma indústria de plásticos, através da caracterização da empresa e do processo, planejamento estratégico e fluxo de informação. 


\subsection{Proposta de implantação de uma metodologia integrada}

Tendo como base estes estudos, desenvolveu-se uma metodologia de aplicação a partir da integração de ME e GP, que seguiu as seguintes etapas: estudo do planejamento estratégico da empresa e seus objetivos; mapeamento do fluxo de informação desde a entrada até a saída; análise do mapeamento com foco nos pontos de desperdício (superprodução, espera, transporte, processamento, estoque e defeitos) durante o processo.

\subsection{Desenvolvimento do estudo de caso}

O estudo de caso é composto pela caracterização do processo escolhido através do seu planejamento estratégico e fluxo de informação produtivo.

\subsubsection{Caracterização da empresa e do processo escolhido}

O processo de corte foi escolhido como escopo de estudo devido a sua grande influência sobre o processo produtivo, por onde se faz a entrada de todo produto na manufatura e representa o processo global no seu conceito amplo do estudo.

\subsubsection{Planejamento estratégico}

O planejamento estratégico da organização para o setor do corte tem como objetivo o aumento da produtividade e a redução de perdas, defeitos e retrabalho.

\section{Quadro 2 - Apresentação dos dados da meta de ação do processo no setor de corte}

\section{PLANEJAMENTO ESTRATÉGICO}

\section{SETOR DE CORTE}

\begin{tabular}{|l|l|l|}
\hline INDICADORES & RESULTADOS & METAS \\
\hline PRODUÇÃO MENSAL & $55.000 \mathrm{~m} / \mathrm{mês}$ & $60.000 \mathrm{~m} / \mathrm{mês}$ \\
\hline$\%$ RETRABALHO & $3 \%$ & Reduzir $5 \%$ o percentual atual \\
\hline$\%$ PERDA/DEFEITO & $1 \%$ & Reduzir $5 \%$ o percentual atual \\
\hline
\end{tabular}

Fonte: Dados da organização estudada, 2012.

Pode-se observar que a meta da produção é de $60.000 \mathrm{~m} / \mathrm{mês}$ no qual se atingiu $55.000 \mathrm{~m} / \mathrm{mês}$ com isso foi alcançado um aumento de 9,09\% (anteriormente era um pouco superior a $50.000 \mathrm{~m} / \mathrm{mês}$ ), a redução de retrabalho tinha como meta $5 \%$, foi obtido $3 \%$, e por último, observamos que houve uma pequena queda na redução de perdas/defeitos em torno de $1 \%$ e a meta era de $5 \%$. 


\subsubsection{Fluxo de informação}

O fluxo de informação analisado considerou as rotinas de envio das ordens de produção para o setor de corte da organização. Para a avaliação do fluxo de informação foram utilizadas ferramentas como entrevista em forma de questionário com os colaboradores envolvidos no processo, para identificação das dificuldades e as lacunas das rotinas do trabalho realizado. No quadro 03 encontram-se os resultados desta aplicação.

\section{Quadro 3 - Dificuldades encontradas nos processos analisados.}

\begin{tabular}{|c|c|c|}
\hline Dificuldade nos Processos & Motivos & Sugestões de Melhorias \\
\hline $\begin{array}{c}\text { Estoque de produto não } \\
\text { acabado, material cortado e } \\
\text { parado aguardando entrar no } \\
\text { processo }\end{array}$ & $\begin{array}{l}\text { Devido a erro de planejamento e a } \\
\text { flexibilidade de atender demandas } \\
\text { específicas }\end{array}$ & $\begin{array}{l}\text { Criar um sistema Kanban } \\
\text { (ferramenta de registro na } \\
\text { produção) que identifique as } \\
\text { ordens com prioridades para a } \\
\text { produção }\end{array}$ \\
\hline $\begin{array}{l}\text { Colaboradores que entendam o } \\
\text { processo e as prioridades da } \\
\text { organização, que sejam } \\
\text { confiáveis e capacitados }\end{array}$ & $\begin{array}{l}\text { Existe uma rotatividade muito grande } \\
\text { neste processo e, devido a isto, os } \\
\text { colaboradores acabam não se } \\
\text { comprometendo com as necessidades } \\
\text { da organização }\end{array}$ & $\begin{array}{c}\text { Desenvolver a sensibilidade do } \\
\text { processo junto aos colaboradores, } \\
\text { criar cursos de capacitação do } \\
\text { trabalho e do processo como um } \\
\text { todo }\end{array}$ \\
\hline $\begin{array}{l}\text { Ferramentas e dispositivos } \\
\text { para realização do trabalho }\end{array}$ & $\begin{array}{l}\text { Mesas de corte com problemas de } \\
\text { estrutura e alguns gabaritos e } \\
\text { dispositivos gastos, o que prejudica } \\
\text { na qualidade do corte }\end{array}$ & $\begin{array}{l}\text { Fazer verificação constante da } \\
\text { qualidade do material utilizado, } \\
\text { com objetivo de reduzir } \\
\text { desperdícios e de produtos saírem } \\
\text { inadequados ao uso do cliente }\end{array}$ \\
\hline $\begin{array}{c}\text { Falta de matéria-prima durante } \\
\text { o processo }\end{array}$ & $\begin{array}{c}\text { Prejudica a produtividade de toda } \\
\text { organização, o desperdício aumento, } \\
\text { pois os lotes são produzidos em } \\
\text { pequenas escalas, e desorganiza o } \\
\text { planejamento produtivo }\end{array}$ & $\begin{array}{l}\text { Montar plano de compra conforme } \\
\text { demanda e pensar em estruturar } \\
\text { um modelo de estoque mínimo }\end{array}$ \\
\hline
\end{tabular}

Fonte: Entrevista com colaboradores do setor, 2012.

Pode-se explicar o quadro 03 observando dificuldades dos processos, motivos e sugestões de melhorias, como ponto importante a ser destacado: a criação de um sistema Kanban que identifique as ordens com prioridades para a produção, a capacitação do trabalho e do processo, a qualidade e o plano de ação da manufatura. Para maior entendimento do negócio da organização e com o objetivo de aprofundar o conhecimento do fluxo de informação, foi desenvolvido um fluxograma de todo o processo produtivo apresentado na figura 02 . 
Figura 2 - Fluxograma do processo organizacional

FLUXO ORGANIZACIONAL

ENTRADA

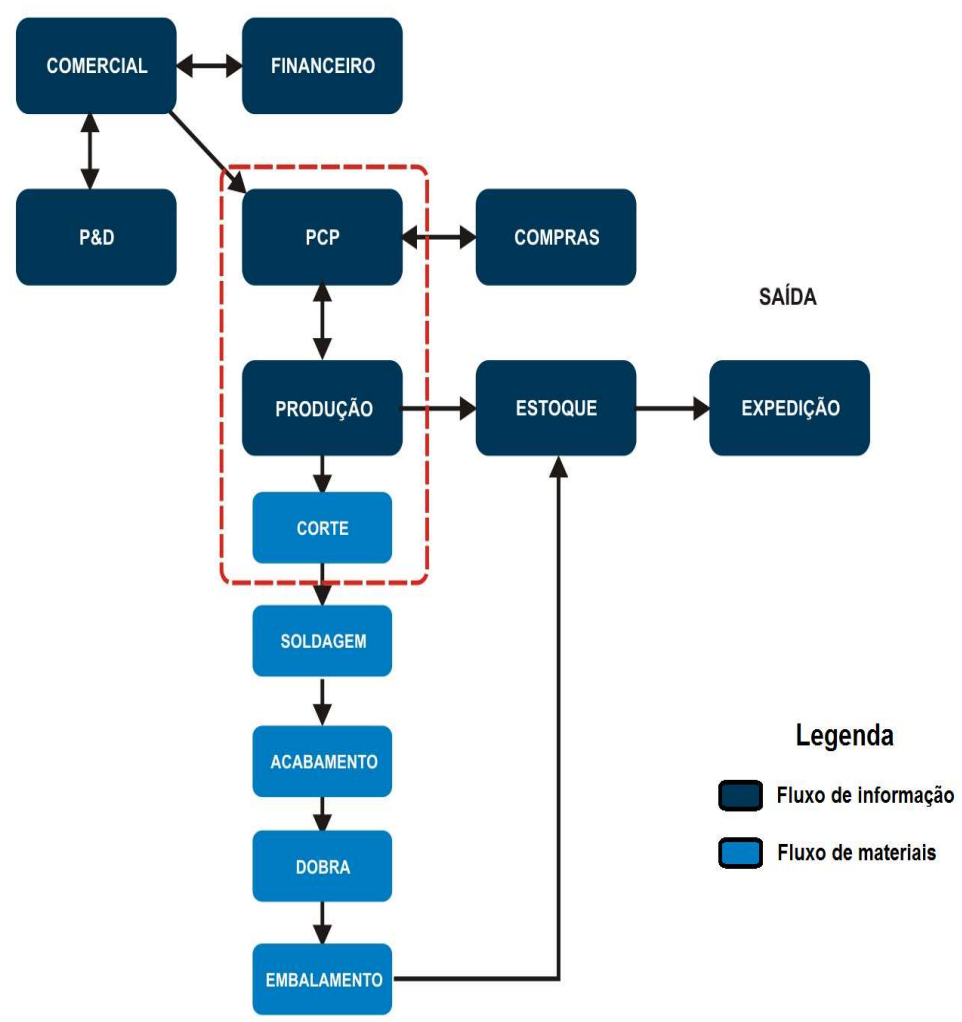

Fonte: Dados da organização estudada.

Observando a figura 02, vê-se um fluxo organizacional composto por dois fluxos: em azul escuro, o fluxo de informação e em azul claro, o fluxo de materiais. Com o objetivo de verificar se a informação chega corretamente para o cliente interno da organização, foi realizada uma pesquisa de satisfação representada no quadro 04.

Quadro 4 - Avaliação da satisfação dos clientes internos.

\begin{tabular}{|c|c|c|c|}
\hline \multicolumn{5}{|c|}{ SATISFAÇÃO DO CLIENTE INTERNO } \\
\hline $\begin{array}{c}\text { ITENS } \\
\text { AVALIADOS }\end{array}$ & RESULTADOS & OBSERVAÇÕES & PONTUAÇÃO \\
\hline Super Produção & Satisfeito & $\begin{array}{c}\text { O setor de corte está com maior capacidade produtiva que } \\
\text { a produção, as ordens de produção sempre são alcançadas } \\
\text { com antecedência }\end{array}$ & 5 \\
\hline Espera & Satisfeito & Não ocorre espera por parte do cliente & 5 \\
\hline Transporte & Regular & $\begin{array}{c}\text { O transporte é feito manualmente até o início do processo, } \\
\text { o que acarreta certa perda de tempo para o início do } \\
\text { processo }\end{array}$ & 2 \\
\hline Processamento & Regular & $\begin{array}{c}\text { Foram identificadas algumas não conformidades em } \\
\text { relação ao solicitado e o realizado, os lotes sempre são } \\
\text { cortados em pares e ocorre com frequência o não } \\
\text { fechamento dos pares }\end{array}$ & 2 \\
\hline
\end{tabular}




\begin{tabular}{|c|c|c|c|}
\hline Estoque & Regular & $\begin{array}{l}\text { Com frequência o material fica parado por dias } \\
\text { aguardando entrar no processo }\end{array}$ & 2 \\
\hline Defeitos & Satisfeito & $\begin{array}{c}\text { O percentual de peças perdidas está dentro das metas da } \\
\text { organização }\end{array}$ & 5 \\
\hline $\begin{array}{l}\text { Fluxo de } \\
\text { informação }\end{array}$ & Satisfeito & $\begin{array}{c}\text { Produção recebe a informação de finalização da ordem de } \\
\text { produção e repassa para Planejamento e Controle da } \\
\text { Produção (PCP) }\end{array}$ & 5 \\
\hline & & Total de Pontos & 26 \\
\hline
\end{tabular}

A avaliação da satisfação dos clientes considerou os quesitos de superprodução, espera, transporte, processamento, estoque, defeitos e fluxo de informação, obtendo pontuação máxima os itens: superprodução, espera, defeito e fluxo de informação.

\subsubsection{Análises de desperdício}

O estudo de desperdício baseou-se nos objetivos do planejamento estratégico da organização e nos dados apresentados anteriormente, e, a partir destes pontos, foram desenvolvidos indicadores de desempenho do processo como: percentual de retrabalho e percentual de perdas decorrente de defeitos. Nas figuras 03 e 04 encontram-se os resultados da análise do percentual de defeitos durante o processo do corte e da análise do percentual de retrabalho durante o processo do corte.

\section{Figura 3 - Análise do percentual de defeitos durante o processo do corte.}

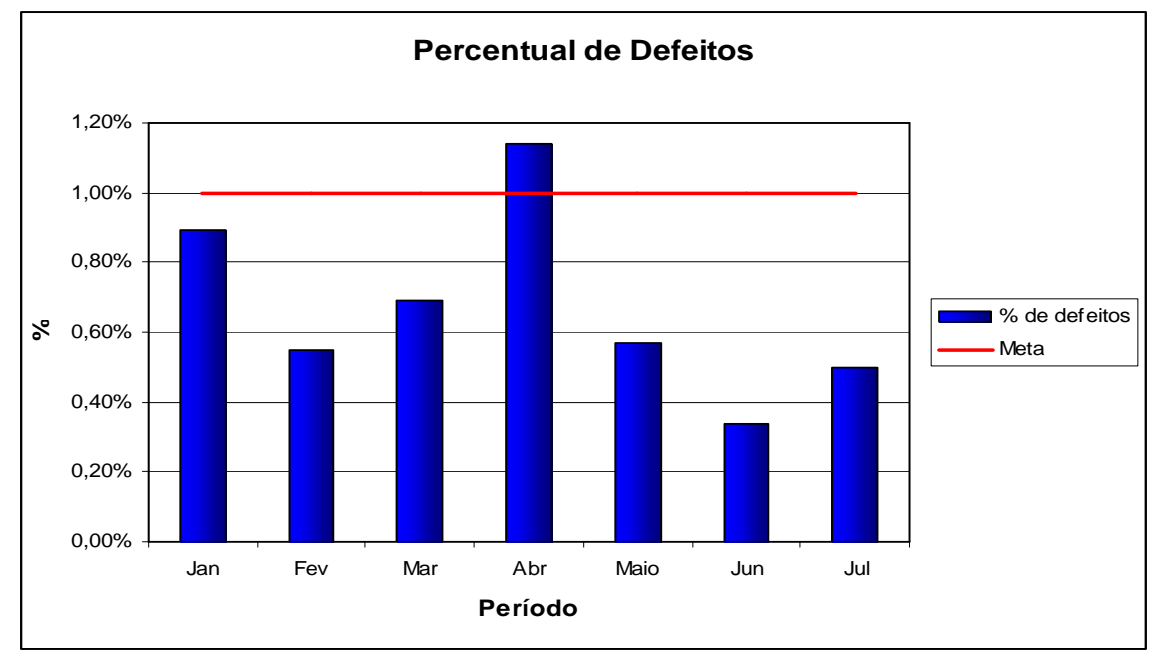

Fonte: Dados da organização estudada, 2012.

Considerando-se a figura 03, a análise do percentual de defeitos durante o processo de corte tem como ponto relevante o mês de abril, no qual foi ultrapassada a meta de $1 \%$.

A figura 04 oferece uma visão do percentual de retrabalho, com maior índice no mês de janeiro. 
Figura 4 - Análise do percentual de retrabalho durante o processo do corte.

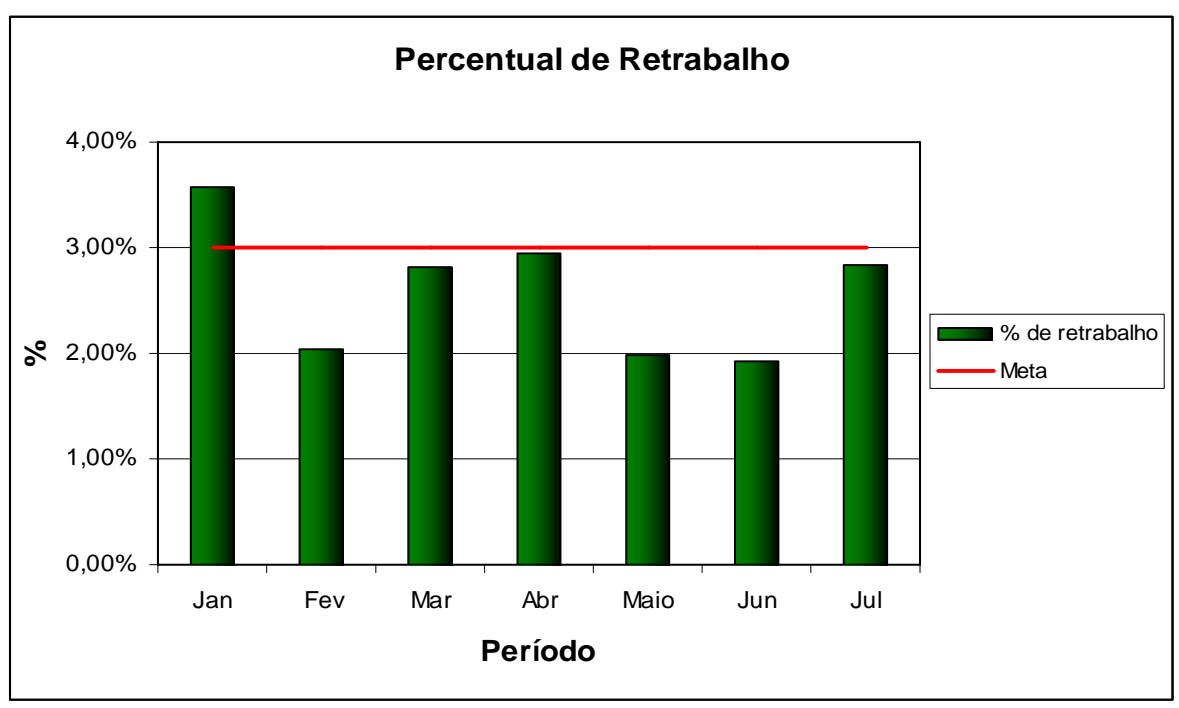

Fonte: Dados da organização estudada, 2012.

\section{CONSIDERAÇÕES FINAIS}

Por meio do levantamento bibliográfico, foi possível identificar a compatibilidade e complementariedade entre as duas ferramentas de gerenciamento: gestão por processos e manufatura enxuta, resultando no desenvolvimento de uma nova metodologia. Esta teve alguns ganhos consideráveis na gestão, que buscou entender o planejamento estratégico e os objetivos da organização, para posterior desenvolvimento de ferramentas para auxiliarem no controle e no monitoramento dos processos, nas sugestões de melhorias e na avaliação da satisfação dos clientes internos.

Estudadas e levantadas às dificuldades e os desperdícios do processo, identificou-se alguns pontos onde a informação ainda é ineficiente e o desperdício de matéria-prima e de tempo é alto. O próximo passo da pesquisa é a implantação das sugestões de melhorias, que a equipe passou para a organização, e a criação de grupos de melhorias contínuas, visando o estudo aprofundado do fluxo de informação de toda organização e a redução dos desperdícios em todas as áreas, pois a organização ganhará em redução de custos e em uma produção mais informada e enxuta para alcançar melhores resultados internos e externos. Por fim, destaca-se que são necessárias mais experiências in loco sobre a metodologia proposta e prática de domínio na sua aplicação organizacional. 


\section{REFERÊNCIAS}

ALUKAL, George. Create a Lean, Mean Machine. Quality Progress, v. 36, nº 4, p. 29-35, 2003

ALVES, M. João. Mrp II e manufatura enxuta: Vantagens, limitações e integração. Anais do ENEGEP: Encontro Nacional de Engenharia de Produção, São Paulo, 2001.

ANDERSSON, R.; ERIKSSON, H; TORSTENSSON, H. Similarities and differences between TQM, six sigma and lean. The TQM Magazine, v. 18, nº 3, p. 282- 296, 2006.

CANDIDO, R.M.; FERREIRA, M.T. e ZUHLKE, R.F. Implantação de gestão por processos: estudo de caso numa gerência de um centro de pesquisa. Anais do ENEGEP: Encontro Nacional de Engenharia de Produção, Rio de Janeiro, 2008.

FREDERICO, G.F. e TOLEDO, J.C. A gestão por processos: um estudo de caso de um operador logístico. Anais do ENEGEP: Encontro Nacional de Engenharia de Produção, Rio de Janeiro, 2008.

GUPTA S. M.; AL-TURKI Y. A.Y.; PERRY R. F. Flexible kanban system. International Journal of Operations \& Production Management, v. 19, n. 10, p. 1065-1093,1999.

GODOY, Arilda Schmidt. Introdução à pesquisa qualitativa e suas possibilidades. Revista de Administração de Empresas - RAE, v. 35, n. 2, p.57-63, 1995.

HARRISON, A.; CHRISTOPHER, M.; VAN HOEK, R. Creating the Agile Supply Chain, Institute of Logistics \& Transport, UK, 1999.

HODGE, G.; ROSS K.G.; JOINES J.A \& THONEY K. Adapting lean manufacturing principles to the textile industry, Production Planning \& Control: The Management of Operations, v. 22, n. 3, p. 237-247, 2011.

JACOBS, G., KIPPER, L. M.; ELLWANGER, M. C.; FROZZA, R.; NARA, E. O. B. Por onde começar a gestão por processos? Uma análise sobre metodologias. Anais do XIV SIMPEP: Simpósio de Engenharia de Produção, Bauru, 2009.

LAMBERT, D. M.; STOCK, J. R.; ELLRAM, L. M. Fundamentals of logistics management. Nova York: McGraw-Hill, 1998.

LIKER, Jeffrey. The Toyota way. USA: McGraw-Hill, 2004.

LOPES, Marco Aurelio Brum; BEZERRA, Marlene Jesus Soares. Fatores que influenciam o sucesso na implantação da gestão de processos em unidades de produção de petróleo e gás. $I V$ Congresso Nacional de Excelência em Gestão, 2008.

MEHTA, Vidhi.; SHAH, Harshit. Characteristics of a Organizational from a Lean Perspective. Engineering Management Journal, v. 17, n. 2, p. 14-19, 2005.

NEVES, José Luis. Pesquisa qualitativa - características, uso e possibilidades. Cadernos de pesquisa em adminsitração, São Paulo, v. 1, n. 3, p. 55-68, 1996. 
PATEL S.; SHAW P.; DALE B.G. Set-up time reduction and mistake proofing methods - A study of application in a small company. Business Process Management Journal, v.7, n. 1, p. 65-75, 2001.

PEREIRA, F. A.; FORNO A. J. D.; TUBINO, D. F.; A flexibilidade no contexto do desenvolvimento de Fábricas inteligentes. Produção Online, Santa Catarina, v. 8, n. 2, 2008.

RAMESH Varun; KODALI Rambabu. A decision framework for maximising lean manufacturing performance. International Journal of Production Research, v. 50, n. 8, 2012.

RIEZEBOS J.; KLINGENBERG. W.; HICKS C. Lean Production and information technology: Connection or contradiction? Computers in Industry, v. 60, n. 4, p. 237-247, 2009.

SHIROSE, Kunio. TPM for workshop leaders. Productivity Press, 1992.

VANTI, Nadia. Ambiente de qualidade em uma biblioteca universitária: aplicação do 5S e de um estilo participativo de administração. Ciência da Informação, Brasília, v. 28, n. 3, p. 333$339,1999$.

VILLIERS, Francois. The Lean, Agile And Worldclass Manufacturing Cookbook. E-book, 2006. Disponível em: <http://www.docstoc.com/docs/1084889/The-LeanAgile-and-WorldClass-Manufacturing-Cookbook> Acesso em: 25 de abr. de 2010.

WOMACK, James; JONES, Daniel. A mentalidade enxuta nas empresas - Lean thinking: elimine o desperdício e crie riqueza. Rio de Janeiro: Campus, 2004. 